\title{
Hydration of Ions in Aqueous Solutions Studied by Infrared
} Spectroscopy. II. Application

\author{
OLOF KRISTIANSSON, ANDERS ERIKSSON and JAN LINDGREN
}

Institute of Chemistry, University of Uppsala, Box 531, S-751 21 Uppsala, Sweden

Infrared spectra of 13 different salt solutions have been studied. OD-stretching bands from isotopically diluted HDO molecules have been obtained using a difference technique by which the absorption from the bulk water is subtracted. One absorption band is found to be associated with each ion. These bands have been interpreted to arise from HDO molecules situated in the first hydration sphere of the ions. Distances of the type $\mathrm{O} \cdots \mathrm{O}, \mathrm{O} \cdots \mathrm{Cl}^{-}, \mathrm{O} \cdots \mathrm{Br}^{-}$are calculated from $v / R(\mathrm{O} \cdots)$ correlation curves.

A method for the study of ion hydration in aqueous solutions using infrared spectroscopy was described in Part I of this series. ${ }^{1}$ The experimental method and subsequent bandshape analysis were presented. In the present paper we give the results from studies of a series of simple ions. The experimental conditions were as stated in Part I, except that in some cases different concentrations were used. The actual concentrations are given in the figure texts for the corresponding spectra.

\section{EXPERIMENTAL RESULTS AND DISCUSSION}

$\mathrm{Mg}^{2+}, \mathrm{Mn}^{2+}, \mathrm{Fe}^{2+}, \mathrm{Ni}^{2+}$ and $\mathrm{Zn}^{2+}$ perchlorates. Difference spectra, of the type described in Part I, for $\mathrm{Mg}^{2+}, \mathrm{Mn}^{2+}, \mathrm{Fe}^{2+}, \mathrm{Ni}^{2+}$ and $\mathrm{Zn}^{2+}$ perchlorates are shown in Fig. 1. These spectra have been used for band-shape analyses using gaussian band-forms. The band parameters are given in Table 1. The standard deviations given in parentheses for $\mathrm{Fe}\left(\mathrm{ClO}_{4}\right)_{2}$ are representative for all cases. The parameters have been scaled to 0.400 molal salt concentrations and $2.0 \%$ HDO.
The band centred at $2623 \mathrm{~cm}^{-1}$ was assigned to absorption from OD stretchings from HDO molecules hydrogen-bonded to the $\mathrm{ClO}_{4}{ }^{-}$ion. ${ }^{1}$ This band is common to all the cases and provides a test on the method, since independent least-

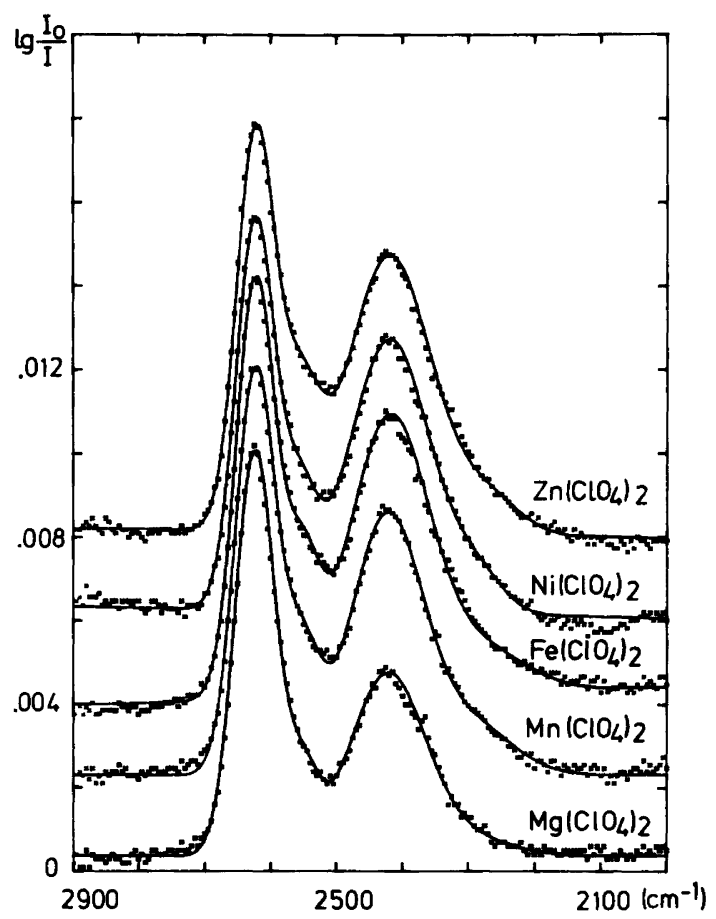

Fig. 1. Difference spectra of 0.4 molal solutions of $\mathrm{Mg}^{2+}, \mathrm{Mn}^{2+}, \mathrm{Fe}_{2}{ }^{+}, \mathrm{Ni}^{2+}$ and $\mathrm{Zn}^{2+}$ perchlorates. Measured spectra are indicated by crosses at intervals of $5 \mathrm{~cm}^{-1}$. The full curves are calculated spectra using band parameters given in Table 1. 
Table 1. Band parameters from least-squares refinements. $\nu_{\mathrm{j}}^{\rho}\left(\mathrm{cm}^{-1}\right)$ is the band position, $c_{\mathrm{j}}$ band height in absorbance, $a_{\mathrm{j}}\left(\mathrm{cm}^{-1}\right)$ width and $A_{\mathrm{j}}=a_{\mathrm{j}} c_{\mathrm{j}}(2 \pi)^{1 / 2}$ the band area $\left(\mathrm{cm}^{-1}\right)$. Estimated standard deviations are given in parentheses for $\mathrm{Fe}\left(\mathrm{ClO}_{4}\right)_{2}$ and apply for all cases.

\begin{tabular}{lllllllll}
\hline Compound & $\nu_{\mathrm{i}}^{\mathrm{o}}$ & $c_{1}$ & $a_{1}$ & $A_{1}$ & $\nu_{2}^{\circ}$ & $c_{2}$ & $a_{2}$ & $A_{2}$ \\
\hline $\mathrm{Fe}\left(\mathrm{ClO}_{4}\right)_{2}$ & $2623(2)$ & $0.01008(9)$ & $29.7(2)$ & 0.750 & $2552(1)$ & $0.00291(7)$ & $26.0(7)$ & 0.190 \\
$\mathrm{Mg}\left(\mathrm{ClO}_{4}\right)_{2}$ & 2624 & 0.00977 & 30.2 & 0.739 & 2552 & 0.00183 & 24.6 & 0.113 \\
$\mathrm{Mn}\left(\mathrm{ClO}_{4}\right)_{2}$ & 2623 & 0.00983 & 30.4 & 0.749 & 2552 & 0.00267 & 27.1 & 0.181 \\
$\mathrm{Ni}\left(\mathrm{ClO}_{4}\right)_{2}$ & 2623 & 0.00934 & 29.7 & 0.695 & 2555 & 0.00229 & 24.9 & 0.143 \\
$\mathrm{Zn}\left(\mathrm{ClO}_{4}\right)_{2}$ & 2623 & 0.00958 & 29.1 & 0.700 & 2555 & 0.00309 & 29.8 & 0.231 \\
\hline $\mathrm{Compound}$ & $v_{3}^{\mathrm{o}}$ & $c_{3}$ & $a_{3}$ & $A_{3}$ & $v_{4}^{\circ}$ & $c_{4}$ & $a_{4}$ & $A_{4}$ \\
\hline $\mathrm{Fe}\left(\mathrm{ClO}_{4}\right)_{2}$ & $2419(1)$ & $0.00653(5)$ & $58.7(4)$ & 0.961 & $2284(3)$ & $0.00102(3)$ & $69.5(2)$ & 0.178 \\
$\mathrm{Mg}\left(\mathrm{ClO}_{4}\right)_{2}$ & 2423 & 0.00436 & 57.2 & 0.625 & 2302 & 0.000415 & 65.5 & 0.067 \\
$\mathrm{Mn}\left(\mathrm{ClO}_{4}\right)_{2}$ & 2423 & 0.00616 & 54.4 & 0.840 & 2296 & 0.00119 & 62.6 & 0.187 \\
$\mathrm{Ni}\left(\mathrm{ClO}_{4}\right)_{2}$ & 2418 & 0.00651 & 60.9 & 0.993 & 2287 & 0.000835 & 39.6 & 0.047 \\
$\mathrm{Zn}\left(\mathrm{ClO}_{4}\right)_{2}$ & 2420 & 0.00680 & 64.1 & 1.092 & 2264 & 0.000829 & 47.7 & 0.099 \\
\hline
\end{tabular}

squares refinements have been made. The band centre and the half-width are reproduced exceedingly well in the different cases. The band heights show a somewhat larger variation than that expected from the standard deviations given in Table 1 which is based on the least aquares refinement. The average band height with standard deviated calculated from the five cases studied is $0.00972(28)$. The standard deviations calculated in these two ways are different since not all parameters could be refined simultaneously; the standard deviations derived from the refinement are underestimated. A relative error of $3 \%$ in the band height is nevertheless a most encouraging result, considering that relatively dilute solutions are used, together with a very low percentage of deuterium.

The other main band in the spectra is associated with $\mathrm{HDO}$ molecules coordinated to the metal ions. In the cases of $\mathrm{Mn}^{2+}, \mathrm{Fe}^{2+}, \mathrm{Ni}^{2+}$ and $\mathrm{Zn}^{2+}$, the band shapes and areas are strikingly similar, indicating a very similar hydration structure. For a 0.46 molal $\mathrm{NiCl}_{2}$ solution, a hydration number of $6.8 \pm 0.8$ for $\mathrm{Ni}^{2+}$ has been reported from neutron scattering. ${ }^{2}$ It is thus very likely that this also applies for $\mathrm{Mn}^{2+}, \mathrm{Fe}^{2+}$ and $\mathrm{Zn}^{2+}$. For $\mathrm{Mg}^{2+}$, the corresponding band area is significantly smaller; only 0.63 of that for $\mathrm{Ni}^{2+}$. A possible explanation for this is that the band intensity is larger for the cases of the transition metal ions due to an increased polarization of the OD bond (see also below). Another possibility is that the hydration number of $\mathrm{Mg}^{2+}$ is four rather than six; contrary to that reported from X-ray scattering studies. ${ }^{2}$

$\mathrm{MgBr}_{2}$ and $\mathrm{MgCl}_{2}$. Difference spectra for $\mathrm{MgBr}_{2}$ and $\mathrm{MgCl}_{2}$ are shown in Fig. 2, the case of $\mathrm{Mg}\left(\mathrm{ClO}_{4}\right)_{2}$ is included for comparison. The hydration band of $\mathrm{Mg}^{2+}$ is here expected to remain unchanged, whereas those of the anions might change. It is seen that the anion hydration

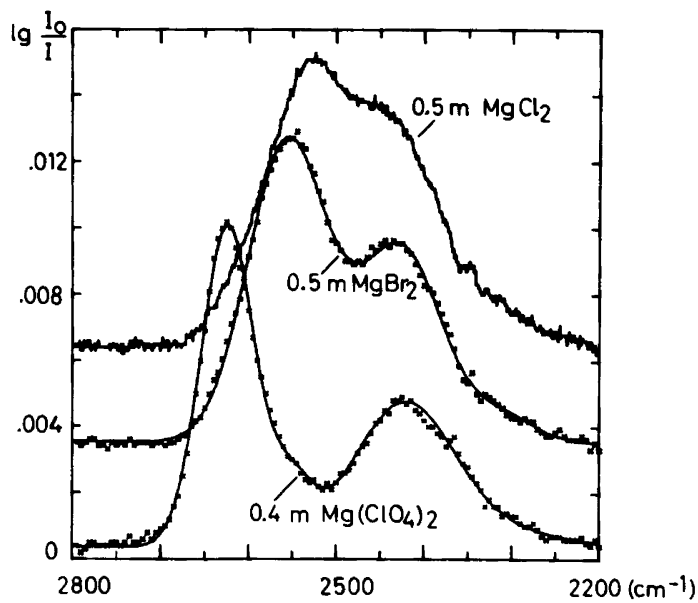

Fig. 2. Difference spectra of $\mathrm{MgCl}_{2}, \mathrm{MgBr}_{2}$ and $\mathrm{Mg}\left(\mathrm{ClO}_{4}\right)_{2}$. For $\mathrm{MgBr}_{2}$ and $\mathrm{Mg}\left(\mathrm{ClO}_{4}\right)_{2}$ the observed spectra are indicated by crosses at 5 $\mathrm{cm}^{-1}$ intervals and calculated spectra as full curves. Only the observed spectrum is shown for $\mathrm{MgCl}_{2}$. 
band approaches that of $\mathrm{Mg}^{2+}$ at $2423 \mathrm{~cm}^{-1}$ in the series $\mathrm{Mg}\left(\mathrm{ClO}_{4}\right)_{2}, \mathrm{MgBr}_{2}$ and $\mathrm{MgCl}_{2}$.

In the model used for the band-shape analysis in Part I, a scale factor $k_{3}$ was included to determine how much of the OD band from HDO in the bulk water should be subtracted; $k_{3}$ was determined by finding the best fit obtained with the least-squares procedure for a systematic variation of scale factor. In the case of $\mathrm{MgBr}_{2}$, good fits were obtained for a rather large variation in the scale factor. The position of the $\mathrm{Mg}^{2+}$ hydration band was thus fixed to $2423 \mathrm{~cm}^{-1}$ as found for $\mathrm{Mg}\left(\mathrm{ClO}_{4}\right)_{2}$ in these calculations. No distinct values for the band heights could be obtained. The position of the $\mathrm{Br}^{-}$hydration band $\left(2557 \mathrm{~cm}^{-1}\right)$ and the band widths of the gaussian bands for $\mathrm{Br}^{-}\left(45 \mathrm{~cm}^{-1}\right)$ and $\mathrm{Mg}^{2+}\left(46 \mathrm{~cm}^{-1}\right)$ were less affected by scale factor changes. The band width of the $\mathrm{Mg}^{2+}$ gaussian band found in $\mathrm{MgBr}_{2}$ is smaller than that found for $\mathrm{Mg}\left(\mathrm{ClO}_{4}\right)_{2}$. It is not possible to ascertain at this stage whether this difference is significant. For $\mathrm{MgCl}_{2}$ no bandshape analysis was attempted, and only the position of the $\mathrm{Cl}^{-}$hydration band $(2538 \pm 10$ $\mathrm{cm}^{-1}$ ) was estimated.

$\mathrm{NaCl}, \mathrm{NaBr}, \mathrm{NaI}$ and $\mathrm{NaClO}_{4}$. Spectra of $\mathrm{NaCl}, \mathrm{NaBr}, \mathrm{NaI}$ and $\mathrm{NaClO}_{4}$ are shown in Fig. 3. Band-shape analysis were not possible in these cases either. Band positions discussed below are therefore subject to the same uncertainty as those for the $\mathrm{Cl}^{-}$hydration band $\left( \pm 10 \mathrm{~cm}^{-1}\right)$. In $\mathrm{NaClO}_{4}$, the band at $2623 \mathrm{~cm}^{-1}$ belongs to the

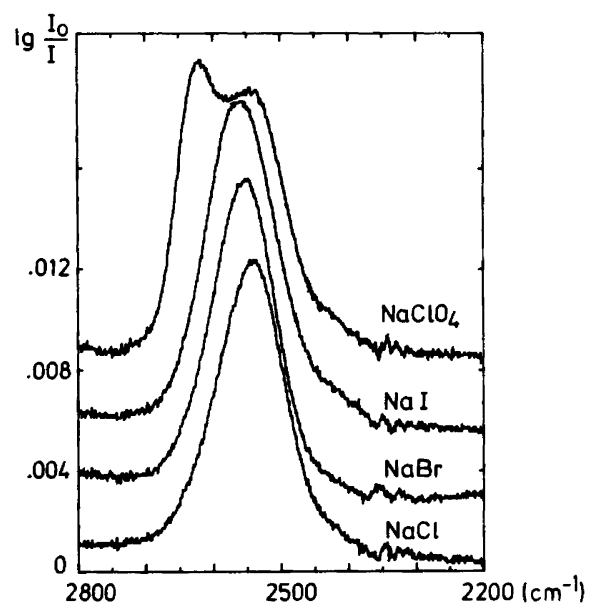

Fig. 3. Difference spectra of 0.6 molal solutions of $\mathrm{NaCl}, \mathrm{NaBr}, \mathrm{NaI}$ and $\mathrm{NaClO}_{4}$.

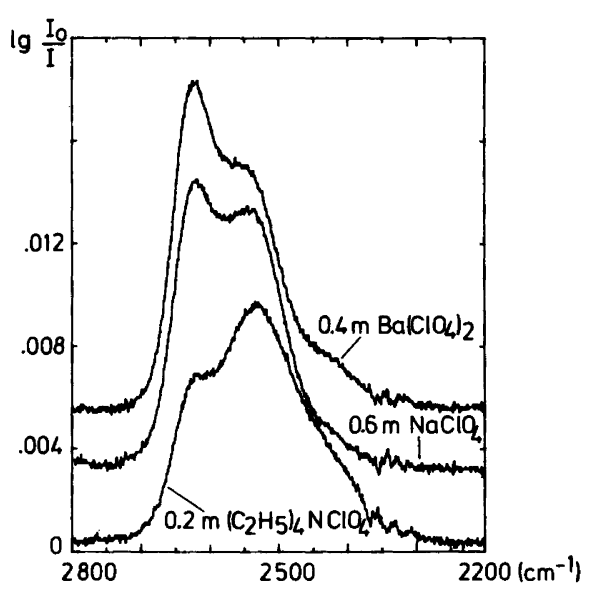

Fig. 4. Difference spectra of $\mathrm{Ba}\left(\mathrm{ClO}_{4}\right)_{2}, \mathrm{NaClO}_{4}$ and $\left(\mathrm{C}_{2} \mathrm{H}_{5}\right)_{4} \mathrm{NClO}_{4}$.

$\mathrm{ClO}_{4}^{-}$ion and that at $2540 \mathrm{~cm}^{-1}$ to the $\mathrm{Na}^{+}$ion. For $\mathrm{NaCl}, \mathrm{NaBr}$ and $\mathrm{NaI}$, the hydration bands from the anion and cation overlap, as expected from the band positions of $\mathrm{Cl}^{-}$and $\mathrm{Br}^{-}$given in the preceding section, such that only one band is visible in each spectrum at 2542, 2552 and 2560 $\mathrm{cm}^{-1}$, respectively. The hydrogen-bond strength between a water molecule and $\mathrm{Cl}^{-}, \mathrm{Br}^{-}$and $\mathrm{I}^{-}$ should decrease in this order. This should cause the corresponding hydration band to be shifted to higher wavenumbers; as is in fact observed.

The estimated halfwidth of the combined hydration bands for $\mathrm{NaCl}$ is $120 \mathrm{~cm}^{-1}$, which is smaller than the value $160 \mathrm{~cm}^{-1}$ for the OD band of HDO in water. This explains earlier observations of spectra of aqueous solutions of $\mathrm{NaCl}^{3}$ where the total OD band from both coordinated and non-coordinated HDO molecules was studied. It was found that the OD band in water was displaced towards higher wavenumbers and narrowed on the addition of $\mathrm{NaCl}$.

$\mathrm{Ba}\left(\mathrm{ClO}_{4}\right)_{2}$ and $\left(\mathrm{C}_{2} \mathrm{H}_{5}\right)_{4} \mathrm{NClO}_{4}$. Spectra of $\mathrm{Ba}\left(\mathrm{ClO}_{4}\right)_{2}$ and $\left(\mathrm{C}_{2} \mathrm{H}_{5}\right)_{4} \mathrm{NClO}_{4}$ are shown in Fig. 4. In the case of $\mathrm{Ba}\left(\mathrm{ClO}_{4}\right)_{2}$, the band from $\mathrm{ClO}_{4}^{-}$ is found at $2623 \mathrm{~cm}^{-1}$. The shoulder at $2540 \mathrm{~cm}^{-1}$ thus belongs to $\mathrm{Ba}^{2+}$.

The hydration of the $\left(\mathrm{C}_{2} \mathrm{H}_{5}\right)_{4} \mathrm{~N}^{+}$ion is expected to be hydrophobic in character, in which the water molecules in the hydration shell are hydrogen-bonded to one another and interact only weakly or not at all with the $\left(\mathrm{C}_{2} \mathrm{H}_{5}\right)_{4} \mathrm{~N}^{+}$ ions. The selection of a suitable scale factor for 


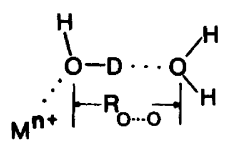

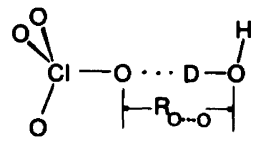

Fig. 5. A schematic drawing of fragments of aggregates in aqueous solution, showing hydration of a metal ion and a perchlorate ion.

the background HDO spectrum is more difficult for $\left(\mathrm{C}_{2} \mathrm{H}_{5}\right)_{4} \mathrm{NClO}_{4}$ than for the metal ions. Some observations can be made however. There is one band at $2540 \mathrm{~cm}^{-1}$ and a shoulder at about 2400 $\mathrm{cm}^{-1}$ which arise from HDO molecules around the $\left(\mathrm{C}_{2} \mathrm{H}_{5}\right) \mathrm{N}^{+}$ion. The shoulder at $2623 \mathrm{~cm}^{-1}$ is from $\mathrm{ClO}_{4}^{-}$. More cases of hydrophobic hydrations clearly have to be studied before any definite conclusions can be drawn.

\section{STRUCTURAL INFORMATION}

It appears from the present results that each ion in a dilute electrolyte solution has a specific hydration structure, giving rise to an absorption band in the infrared spectra. In Fig. 5 a schematic drawing is given of fragments of aggregates in aqueous solution showing the hydration of a metal ion and a perchlorate ion. Vibrations of the OD bonds of the HDO molecules in the two cases shown are associated with the absorption bands. The arrangements shown in Fig. 5 should be considered as average configurations from a distribution of geometries. In the following we will first discuss some geometric estimates of the average structure as obtained from the band centres and then how to obtain information as to the structural distributions from the band-shapes.

Average $\mathrm{O} \cdots \mathrm{O}, \mathrm{O} \cdots \mathrm{Cl}$ and $\mathrm{O} \cdots \mathrm{Br}$ distances. Most structural studies of aqueous electrolyte solutions have been made using $X$-ray and neutron scattering. It would be most valuable if the present spectroscopic data could be used to calculate distances which in some cases could be directly compared to the scattering results.

In order to convert our band positions to distances, we use data from measurements made on crystalline hydrates. A large amount of spectroscopic and structural data exists on hydrates containing $\mathrm{O} \cdots \mathrm{O}$ distances. For $\mathrm{O} \cdots \mathrm{Cl}^{-}$ and $\mathrm{O} \cdots \mathrm{Br}^{-}$the situation is less favourable. The data on $\mathrm{O} \cdots \mathrm{O}$ distances have been used to

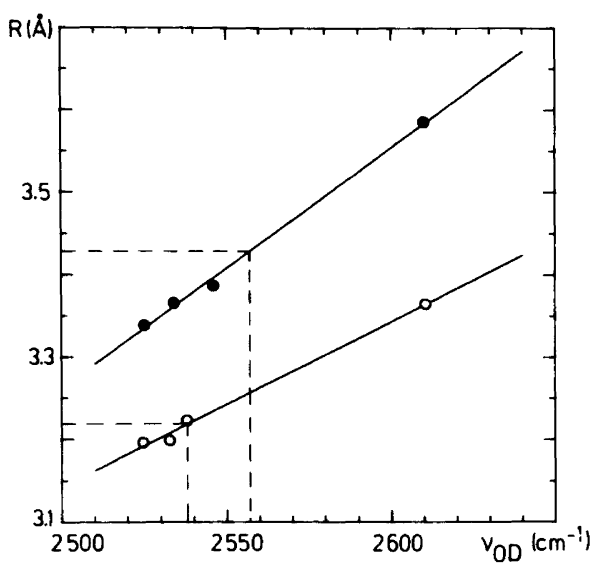

Fig. 6. Plots of $R_{\mathrm{O}} \ldots \mathrm{Cl}^{-}$(data from Ref. 5 and 6, unfilled circles) and $R_{\mathrm{O}} \cdots \mathrm{Br}$ (data from Ref. 7 and 8, filled circles). Estimates of the $R_{\mathrm{O} \cdots \mathrm{Br}}$ and $R_{\mathrm{O} \ldots \mathrm{Cr}}$ distances in aqueous solution from the measured $v_{\mathrm{OD}}$ values are indicated by dashed lines.

prepare correlation curves for $R_{\mathrm{O}} \ldots \mathrm{o}$ versus $v_{\mathrm{OD}}$. We will use the one given in Ref. 4 , where an equation of the form $R_{\mathrm{O}} \ldots \mathrm{O}=(16.01-$ $\ln \left(2727-v_{\mathrm{OD}}\right) / 3.73$ was obtained. The distances calculated from this equation using our measured $v_{\mathrm{OD}}$ values are given in Table 2 .

In the absence of similar correlation information for $\mathrm{O} \cdots \mathrm{Cl}^{-}$and $\mathrm{O} \cdots \mathrm{Br}^{-}$distances, we have

Table 2. Wavenumbers of band maxima for $\mathrm{O}-\mathrm{D}$ stretchings of HDO molecules bonded to various ions and derived $\mathrm{O} \cdots \mathrm{O}$ distances (see text and Fig. 5). Wavenumbers marked with an asterisk are less accurate.

\begin{tabular}{lll}
\hline Ion & $\begin{array}{l}\text { Wavenumber } \\
\left(\mathrm{cm}^{-1}\right)\end{array}$ & $\begin{array}{l}\text { Distance } \\
(\AA)\end{array}$ \\
\hline $\mathrm{Mg}^{2+}$ & 2423 & 2.76 \\
$\mathrm{Ba}^{2+}$ & $2540^{*}$ & 2.89 \\
$\mathrm{Mn}^{2+}$ & 2423 & 2.76 \\
$\mathrm{Fe}^{2+}$ & 2419 & 2.76 \\
$\mathrm{Ni}^{2+}$ & 2418 & 2.76 \\
$\mathrm{Zn}^{2+}$ & 2420 & 2.76 \\
$\mathrm{Na}^{+}$ & $2540^{*}$ & 2.89 \\
$\mathrm{Et}_{4} \mathrm{~N}^{+}$ & $2530^{*}$ & 2.88 \\
$\mathrm{ClO}_{4}^{-}$ & 2623 & 3.05 \\
$\mathrm{Cl}^{-}$ & $2538^{*, a}$ & 3.22 \\
$\mathrm{Br}^{-}$ & $2557^{b}$ & 3.43 \\
\hline
\end{tabular}

${ }^{a} \mathrm{O} \cdots \mathrm{Cl}^{-}$distance. ${ }^{b} \mathrm{O} \cdots \mathrm{Br}^{-}$distance.

Acta Chem. Scand. A 38 (1984) No. 8 
used results on the crystalline hydrates $\mathrm{NaCl}$. $2 \mathrm{H}_{2} \mathrm{O}^{5,6}$ and $\mathrm{NaBr} \cdot 2 \mathrm{H}_{2} \mathrm{O}^{7,8}$. $\mathrm{R}_{\mathrm{O}} \cdots \mathrm{Br}$ and $\mathrm{R}_{\mathrm{O}} \cdots \mathrm{Cr}$ are plotted against $v_{\mathrm{OD}}$ in Fig. 6 . The estimated distances for $R_{\mathrm{O}} \cdots \mathrm{Cr}$ and $R_{\mathrm{O}} \cdots \mathrm{Br}$ in solution are also given in Table 2 .

A review of X-ray and neutron scattering from aqueous solutions of electrolytes is given in Ref. 2 , where distances for a large number of ions have been tabulated. Our calculated values $R_{\mathrm{O} \cdots \mathrm{Cl}}=3.22(2) \quad \AA$ and $R_{\mathrm{O}} \ldots \mathrm{Br}=3.43(2) \AA$, where the uncertainty indicated by the numbers in parentheses is calculated from uncertainty in band positions $\left(+10 \mathrm{~cm}^{-1}\right)$, agree well with the values given in Table 1 of Ref. 2 (3.10-3.35 $\AA$ for $\mathrm{Cl}^{-}$and 3.14-3.43 $\AA$ for $\mathrm{Br}^{-}$). The most obvious comparison for $\mathrm{O} \cdots \mathrm{O}$ distances can be made for pure water where our calculated value for $R_{\mathrm{O}} \ldots \mathrm{O}$ at $20^{\circ} \mathrm{C}$ is $2.86 \AA$. This is in good agreement with the value obtained from $\mathrm{X}$-ray scattering studies ${ }^{9}\left(2.84 \AA\right.$ at $\left.25^{\circ} \mathrm{C}\right)$.

The distances $\mathrm{Me} \cdots \mathrm{O}$ are given for metal ions in Table 1 of Ref. 3. These cannot be obtained from our spectroscopic data. On the other hand, the $\mathrm{O} \cdots \mathrm{O}$ distances (Fig. 5) are not readily obtained by X-ray or neutron scattering methods. These distances are nevertheless important since they give a direct measure of the strength of the interaction between the hydration shell of the ion and the surrounding water molecules. From Table 2 we can conclude that this interaction is the same $\left(R_{\mathrm{O}} \cdots \mathrm{O}=2.89 \AA\right)$ for monovalent $\mathrm{Na}^{+}$ and divalent $\mathrm{Ba}^{2+}$. The interactions for $\mathrm{Na}^{+}$and $\mathrm{Ba}^{2+}$ are thus slightly weaker than the average interaction between molecules in pure water $\left(R_{\mathrm{O} \cdots \mathrm{O}}=2.86 \AA\right)$. The other divalent metal ions studied indicate an interaction which is considerably stronger: $R_{\mathrm{O}} \cdots \mathrm{O}=2.76 \AA$. This is as for water molecules in ordinary ice.

\section{STRUCTURAL DISTRIBUTIONS}

A probability distribution of the $\mathrm{O} \cdots \mathrm{O}$ distances $[P(R)]$ can be obtained in principle using the observed band-shapes and the correlation relation for $R_{\mathrm{O}} \ldots \mathrm{O}$ versus $v_{\mathrm{OD}}$. The equations involved are:

$P(R)=C a(v)(\mathrm{d} v / \mathrm{d} R)$ and $\int_{0}^{\infty} P(R) \mathrm{d} R=1$,

where $a(v)$ is the absorbance and $C$ a normalization constant. These equations were first proposed by Wall and Hornig ${ }^{10}$ and also used by
Falk. ${ }^{11}$ This procedure can be used only if the variation of the absorptivity with frequency across the band is constant. This is not so, however; it is well-known that the intensity of $\mathrm{OH}(\mathrm{OD})$ stretching bands increase with increasing hydrogen-bond strength. Glew and Rath ${ }^{12}$ have studied the $\mathrm{OH}$ stretching band intensity for water molecules bonded to different acceptors. They found a linear increase in intensity as a function of $v$ in the wavenumber interval investigated. This intensity increase was ten-fold between weakly bonded and strongly bonded water molecules. We are currently working on a similar study of OD stretchings. Only a brief remark will be made here concerning the $\mathrm{O} \cdots \mathrm{O}$ distributions. The rather narrow OD band for the perchlorate ion as compared to that for pure water would, at first sight, give the impression of a narrow $\mathrm{O} \cdots \mathrm{O}$ distribution around the $\mathrm{ClO}_{4}^{-}$ion. If we calculate $(\mathrm{d} R / \mathrm{d} v)$ from the correlation equation given above for $v=2623$ and $2504 \mathrm{~cm}^{-1}$ they have the ratio 2:1. From the half widths $\left(\Delta v_{1 / 2}\right)$ of the bands, 70 and $150 \mathrm{~cm}^{-1}$, and by approximating the halfwidth for the $\mathrm{O} \cdots \mathrm{O}$ distributions with $\mathrm{d} R / \mathrm{d} v \Delta v_{1 / 2}$, we see that rather similar distributions would result.

Hydration numbers of the ions. The number of water molecules coordinated to an ion is an important quantity which is, in principle, available from the band ares. We must know the functional variation of intensity with band position, however. When comparing the hydration bands of $\mathrm{Ni}^{2+}$ and $\mathrm{Mg}^{2+}$ above it was noted that larger intensity could possibly be expected for $\mathrm{Ni}^{2+}$ due to an increased polarization of the water molecules coordinated. The same reasoning should then also apply to the force constants of the water molecules leading to different band positions in the two cases, which is contrary to our result. We are presently performing theoretical calculations of band intensities and force constants for the systems $\mathrm{Mg}^{2+}-\mathrm{H}_{2} \mathrm{O}$, $\mathrm{Ni}^{2+}-\mathrm{H}_{2} \mathrm{O}$ and $\mathrm{Zn}^{2+}-\mathrm{H}_{2} \mathrm{O}$ to get more information on this question. Furthermore, the HDO molecules are distributed between the bulk water and the hydrated ions; more work involving the variation of salt and deuterium concentrations must be done before hydration numbers can be calculated. 


\section{CONCLUSIONS}

From the infrared spectra of the 13 salts studied involving 12 different ion-types, we conclude that each ion has a hydration structure giving rise to specific absorption bands. This is shown by the consistency between the bands from ions common to two or more salts. Visual inspection of the spectra gives an overall picture of the hydration structures in the solutions. Detailed structural information has been derived in terms of distances of the type $R_{\mathrm{O} \cdots \mathrm{O}}, R_{\mathrm{O} \cdots \mathrm{Cl}^{-}}$, and $R_{\mathrm{O}} \ldots \mathrm{Br}$ - where in some cases comparisons has been made and agreement found with data from $\mathrm{X}$-ray and neutron scattering studies. $R_{\mathrm{O}} \cdots \mathrm{O}$ distances between the water molecules in the first hydration shell and the surrounding water have been obtained; these are distances which are very difficult to obtain by diffraction methods. In contrast to diffraction methods, only O-D bonds are involved in the spectroscopic studies; it should thus be possible to extend the present method to study the hydration of more complex ions.

Acknowledgements. This work has been supported by grants from the Swedish Natural Science Research Council and the Knut and Alice Wallenberg foundation which are hereby gratefully acknowledged.

\section{REFERENCES}

1. Kristiansson, $\mathrm{O}$, Eriksson, A. and Lindgren, J. Acta Chem. Scand. B 38 (1984) 609.

2. Enderby, J. E. and Neilson, G. W. In Franks, F., Ed., Water. A Comprehensive Treatise, Plenum, New York-London 1979, Vol. 6, p. 1.

3. Wyss, H. R. and Falk, M. Can. J. Chem. 48 (1970) 607.

4. Berglund, B., Lindgren, J. and Tegenfeldt, J. J. Mol. Struct, 43 (1978) 179.

5. Klewe, B. and Pedersen, B. Acta Crystallogr. B 30 (1974) 2363.

6. Ford, T. A. and Falk, M. J. Mol. Struct. 3 (1969) 445.

7. Tegenfeldt, J., Tellgren, R., Pedersen, B. and Olovsson, I. Acta Crystallogr. B 35 (1979) 1679.

8. Schiffer, J. Thesis, Princeton University, New Jersey 1963; Diss. Abstr. 25 (1964) 2786.
9. Narten, A. H. and Levy, H. A. Science 165 (1969) 447.

10. Wall, T. T. and Hornig, D. F. J. Chem. Phys. 43 (1965) 2079.

11. Falk, M. In Proceedings of the Electrochemical Society, Symposium on Chemistry and Physics of Aqueous Solutions, Electrochemical Society, Toronto 1975, p. 19.

12. Glew, D. N. and Rath, N. S. Can. J. Chem. 49 (1971) 837.

Received February 27, 1984. 